\title{
Delta Change Method with Cyclic Covariate Generalized Extreme Value Model for Downscaling Extreme Rainfall
}

\author{
Syafrina Abdul Halim
}

\begin{abstract}
In meteorological data, lots of variables have annual, seasonal or diurnal cycles. These would be based on different climatic patterns in different seasons rising sea levels. The delta change approach is one of the statistical downscaling methods that used to downscale global climate model data in order to use it as a future input for hydrological models and flood risk assessment. In this work, a non-stationary GEV model with cyclic covariate structure for modelling magnitude and variation of data series with some degrees of correlation for real-world applications is proposed. All extreme events were calculated assuming that maximum annual daily precipitations follow the $G E V$ distribution. The method makes it possible to identify and estimate the impacts of multiple time scales-such as seasonality, interdecadal variability, and secular trends-throughout the area, scale, and shape parameters of extreme sea level probability distribution. The incorporation of seasonal effects describes a huge amount of data variability, permitting the methods involved to be estimated more efficiently. Next, the technique of deltachange was implemented to the mean annual rainfall and also the regular rainfall occurrences of 5,10,20,50 and 100 years of return. The capability of the proposed model will be tested to one rainfall station in Sabah. The new model suggesting improvement over the stationary model based on the p-value which is highly significant (approximate to 0). GEV model with cyclic covariate on both location and scale parameters is able to capture the seasonality factor in rainfall data. Hence, a reliable delta-change model has been developed in this study. This could produce more accurate projection of rainfall in the future.
\end{abstract}

Index Terms: covariate, cyclic, delta-change, generalized extreme value, rainfall.

\section{INTRODUCTION}

Many variables have annual, seasonal or diurnal cycles in meteorological data. These will be due to various climatic patterns in different seasons, or even due to longer-term trends due to climate change. Statistical downscaling approach is one of the approaches that is widely used to estimate the future rainfall. Statistical downscaling is a twostep process consisting of Statistical downscaling is a twostep process consisting of 1) statistical relationship development among local climate variables and large-scale predictors, 2) applying such relationships to large-scale outputs in order to simulate future local climate characteristics[1]. One of the statistical downscaling methods is called as delta-change method.

Revised Manuscript Received on June 22, 2019.

Syafrina Abdul Halim, Department of Mathematics, Faculty of Science, Universiti Putra Malaysia, 43400 Serdang, Selangor, Malaysia
A common method of dealing with General Circulation Model (GCM) outputs inadequacies (known as the delta change method) is to compute differences between current and future GCM simulations and add these changes to observed time-series [e.g., 2,3]. The delta change method is the primary future scenario generation technique suggested for use in the U.S. National Assessment (see http://www.nacc.usgcrp.gov/). Applying the delta change method assumes that GCMs more reliably simulate relative changes rather than absolute values. In the modeling of cyclic changes in threshold exceedance, it is useful to specify a model with different parameters in each cycle.

The generalized extreme value (GEV) distribution has been employed widely in describing flood characteristics due to its capability in analyzing hydrologic phenomena for instance flood events, which are of particular interest to the fields of engineering and water resources. Traditionally, the GEV distribution is fit assuming that the underlying process is stationary in time, with observations that are independent and identically distributed (IID). However, according to Towler et al. [4], GEV has become generally accepted that climate variability can play a significant role in the magnitude and frequency of extreme streamflow events. Natural modes of interannual and interdecadal variability (e.g., the El Niño phenomenon) have been found to influence flood frequency. Furthermore, evidence of longterm trends, such as from global warming, has undermined the long-held assumption of stationarity [4].

Accurate methods are required to accurately capture the non-stationary climate. Several studies have developed nonstationary GEV approaches in hydrological area [4]. Sarr et al. [5] has applied two different statistical downscaling techniques to the outputs of four regional climate models at six selected precipitation stations in Senegal. The stationary GEV model was presented and the estimated parameters were calculated in the study. A non-stationary GEV model with cyclic covariate structure is proposed in this work to model data series magnitude and variation with some degrees of correlation for real-world applications. All extreme events were calculated assuming that maximum annual daily precipitations follow the GEV distribution. The method makes it possible to identify and estimate the impacts of multiple time scales-such as seasonality, interdecadal variability, and secular trends-throughout the area, scale, and shape parameters of extreme sea level probability distribution.

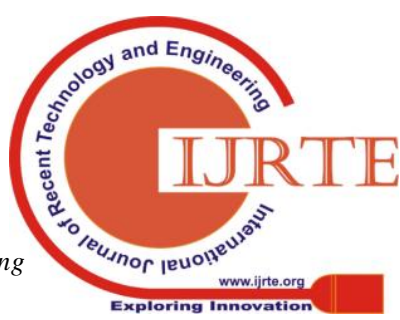


The incorporation of seasonal effects describes a huge amount of data variability, permitting the methods involved to be estimated more efficiently. Next, the technique of delta-change was implemented to the mean annual rainfall and also the regular rainfall occurrences of 5, 10, 20, 50 and 100 years of return. Hence, the objective of the study is to fit the point process (PP) model with the cyclic trend in location and scale parameters of GEV model. Then, delta change that incorporates the proposed GEV with cyclic covariate will be applied to estimate the future rainfall for 2year, 5-year, 10-year, 50-year and 100-year.

\section{METHODOLOGY}

In this study, the GEV is used to model maximum daily precipitations. The GEV distribution has an interesting asymptotical behaviour and is commonly used to model extreme events. The extreme value theory (EVT) provides the convergence of the extremes to the GEV distributions despite the original distribution of the daily data. The GEV distribution combines the Gumbel, Fréchet and Weibull distributions of extreme values [6],

$$
F(x)= \begin{cases}\exp \left[-\left(1-\frac{\kappa}{\alpha}(x-\mu)^{\frac{1}{\kappa}}\right)\right] ; & \kappa \neq 0 \\ \exp \left[-\exp \left(-\left(\frac{x-\mu}{\alpha}\right)\right)\right] ; & \kappa=0\end{cases}
$$

where $\mu, \alpha$ and $\kappa$ are the location, the scale and the shape parameters, respectively. When $\kappa<0$, the GEV corresponds to the Fréchet distribution and can be fitted to heavy tailed behaviour. The $\boldsymbol{\kappa}>0$ represents the Weibull distribution and is used to fit left skewed samples. The case, $\kappa=0$ corresponds to the Gumbel distribution and has moderate right tail with two parameters, scale and location [7]. The GEV parameters are estimated with the Maximum Likelihood Estimator (MLE) method.

Delta change method is based on the ratio between the periods 1991-2003 and 2004-2015 of the T-year rainfall calculated using GCM simulations. For a given station and a given GCM, the delta-change technique is applied in a similar way as in Tramblay et al. [8] and Sarr et al. [9]. However, there is a slight improvement on this method where the cyclic covariate is incorporated in the GEV. The point process model is fitted with the cyclic trend in location and scale and these location and scale parameters are obtained from GEV reparameterization. The location parameter can be expressed as

$$
\mu(t)=\mu_{0}+\mu_{1} \sin \left(\frac{2 \pi t}{T}\right)+\mu_{2} \cos \left(\frac{2 \pi t}{T}\right),
$$

while the scale parameter is

$$
\log \sigma(t)=\sigma_{0}+\sigma_{1} \sin \left(\frac{2 \pi t}{T}\right)+\sigma_{2} \cos \left(\frac{2 \pi t}{T}\right)
$$

and shape parameter is

$\kappa(t)=\kappa$
The mean daily precipitation and the $\mathrm{T}$-year return period precipitation $\left(\mathrm{P}_{\mathrm{T}}\right.$, hist, $\left.\mathrm{GCM}\right)$ for $\mathrm{T}=5,10,20,50,100$ years are calculated using the proposed GEV with cyclic covariate which's parameters are obtained using their maximum likelihood estimator. The future T-year precipitation is estimated as

$$
P_{T_{\text {f fut delta }}}=P_{T_{q} \text { fut }, G C M} \frac{P_{T_{\imath}, \text { hist }, \text { obs }}}{P_{T_{z} \text { hist }, G C M}}
$$

GCMs realizations were obtained from the dataset compiled in the World Climate Research Programme's (WCRP's), Coupled Model Intercomparison Project phase 5 (CMIP5). The selected GCMs that will be used in this study are GFDL-CM3 (United States), IPSL-CM5A-LR (Paris, France), CanESM2 (Canada), HadGEM2 (United Kingdom) with Representative Concentration Pathways (RCPs) of 8.5. There is no guideline to choose the best GCM models, hence GCMs are randomly selected in this study. The proposed method is applied on daily rainfall at Kudat JPS, Sabah station.

\section{RESULTS AND DISCUSSIONS}

Figure 1 shows the scatter plot of daily rainfall data between the years 1991 and 2015. Table 1 shows the descriptive statistics of monthly rainfall data. December recorded the highest mean rainfall amount which is 11.918 $\mathrm{mm}$ /day followed by January $(11.611 \mathrm{~mm} /$ day $)$, November $(8.903 \mathrm{~mm} /$ day $)$ and February $(5.851 \mathrm{~mm} /$ day $)$. It is interesting to note that these months correspond to the northeast monsoon season that brings heavier rainfall to the most areas in Malaysia. It is also can be seen little amount of mean rainfall was recorded during the month of May, June, July and August. This period corresponds to the southwest monsoon season which normally known as dry period. Meanwhile, the rest of the months (March, April, September and October) are known as inter-monsoon season. Maximum daily rainfall amount was recorded during March which is $244.5 \mathrm{~mm} /$ day. This is due to the transformation season (from the northeast monsoon to the southwest monsoon) that is influenced by many meteorological factors such as wind. Flash floods frequently occurred during this month where most of the areas in Malaysia received an intense rainfall in a relatively short period [10].

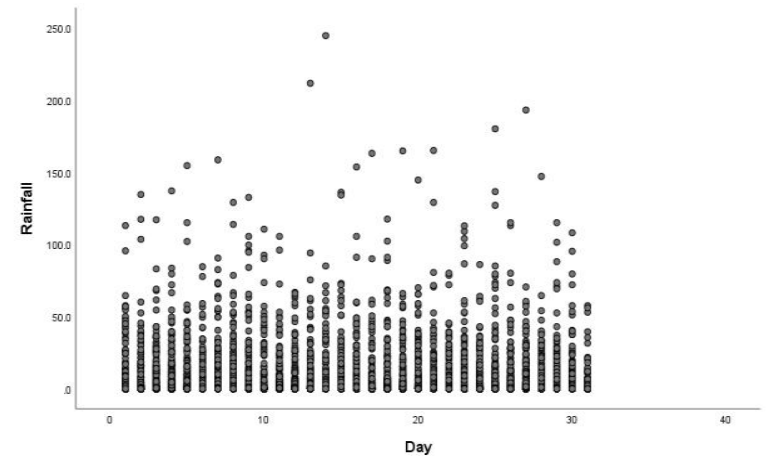

Fig. 1 Scatter plot of daily rainfall data (1991-2015)

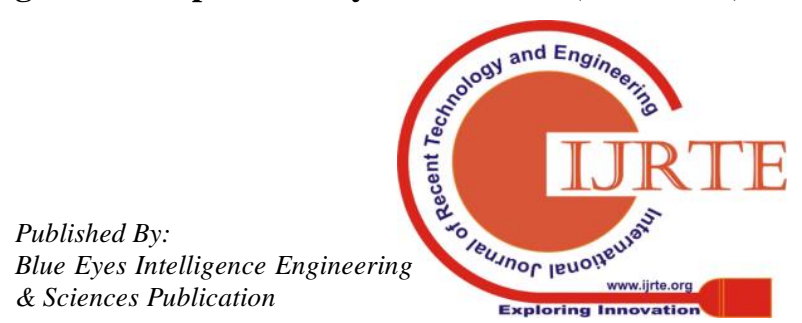


As seen in Table 1, January and December recorded higher values of standard deviation. This represents that the variability of the rainfall amount is quite high as compared to the other months. Meanwhile, each month shows positive skewness which means that the shape of the distribution of monthly rainfall series is skewed to the right. This is also supported by histogram of daily rainfall in Figure 2. Both of the mean of daily rainfall and the standard deviation of daily rainfall between the years of 1991 and 2015 is $5.88 \mathrm{~mm}$ /day and $15.25 \mathrm{~mm} /$ day, respectively. Higher value of standard deviation might be due to extreme data points (extreme rainfall) received in a certain month.

Table. 1 Descriptive statistics of monthly rainfall data

\begin{tabular}{|l|l|l|l|l|l|}
\hline Month & Mean & $\begin{array}{l}\text { Std. } \\
\text { Deviation }\end{array}$ & Max & Min & Skewness \\
\hline Jan & 11.611 & 23.7498 & 211.5 & 0 & 3.501 \\
\hline Feb & 5.851 & 16.4731 & 158.5 & 0 & 4.993 \\
\hline Mar & 5.102 & 17.8978 & 244.5 & 0 & 7.534 \\
\hline Apr & 2.435 & 9.3528 & 154.5 & 0 & 8.490 \\
\hline May & 2.913 & 8.5699 & 95.2 & 0 & 4.974 \\
\hline Jun & 3.851 & 10.2087 & 104.0 & 0 & 4.582 \\
\hline Jul & 4.419 & 10.8423 & 78.5 & 0 & 3.639 \\
\hline Aug & 3.787 & 9.5493 & 79.5 & 0 & 3.734 \\
\hline Sep & 3.940 & 9.1916 & 84.5 & 0 & 3.740 \\
\hline Oct & 5.756 & 12.8786 & 108.0 & 0 & 3.708 \\
\hline Nov & 8.903 & 16.1943 & 136.0 & 0 & 3.073 \\
\hline Dec & 11.918 & 23.0271 & 180.0 & 0 & 3.261 \\
\hline Total & $\mathbf{5 . 8 8 6}$ & $\mathbf{1 5 . 2 5 2 0}$ & $\mathbf{2 4 4 . 5}$ & $\mathbf{0}$ & $\mathbf{5 . 0 8 7}$ \\
\hline
\end{tabular}

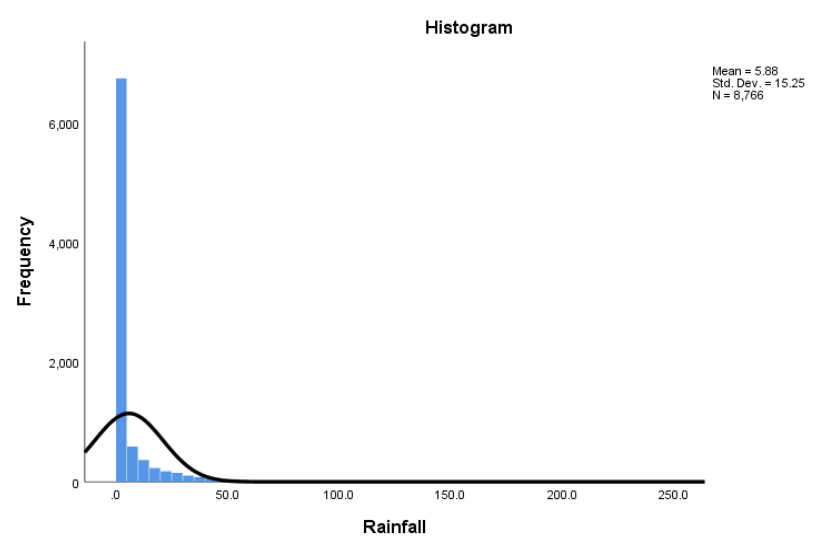

Fig. 2 Histogram of daily rainfall (1991-2015)

Next, the PP design is integrated to the data with no covariations and then a seasonally differing location parameter, as well as seasonally differing scale parameters; In addition to a probability-ratio test for seasonally varying covariate inclusion. The threshold of rainfall for the PP model is $90 \%$ percentile value which is $18.5 \mathrm{~mm}$. The $\mathrm{p}$ value for the probability-ratio statistics comparing the stationary fit with the one incorporating seasonality in the location parameter is less than $2.2 \times 10^{-16}$ means that the addition of seasonality in the parameter of the scale is significant. Also highly significant is the additional inclusion of the scale parameter seasonality which suggests that the model with seasonality must be considered in both terms. Using the GEV re-parameterization approach, the estimated parameters is shown in Table 2.
Table. 2 Estimated parameters of GEV with cyclic covariate

\begin{tabular}{|l|l|l|}
\hline Parameter & $\begin{array}{l}\text { Estimated } \\
\text { value }\end{array}$ & $\begin{array}{l}\mathbf{9 5 \%} \text { Confidence } \\
\text { Interval }\end{array}$ \\
\hline Location, $\boldsymbol{\mu}$ & 113.43 & $(102.69,124.17)$ \\
\hline Scale, $\alpha$ & 33.68 & $(26.28,41.07)$ \\
\hline Shape, $\boldsymbol{\kappa}$ & 0.14 & $(0.06,0.22)$ \\
\hline
\end{tabular}

The estimated shape parameter is 0.14 which is greater than 0. This concludes that the GEV with Fréchet distribution is the most suitable model for the selected rainfall station. The $95 \%$ confidence interval also shows that all the estimated parameter values are not 0 . The range of predicted changes as shown in Table 3 ranges of very low values (less than 2 percent) to very high values (92.55 percent) in the range of data uncertainty. When smaller changes of few percent may be regarded as nonsignificant, those above 10 percent strongly recommend future impact. The projected changes are mostly positive which represents higher rainfall amount in future. The projected changes are highly significant in the late future period, 2081-2100 as compared to the early future period (2006-2049) and the intermediate future period (2050-2080).

Table. 3 Return level and projected changes of rainfall for (i) early future period (2006-2049), (ii) intermediate future period (2050-2080) and (iii) late future period (2081-2100)

(i)

\begin{tabular}{|c|c|c|c|c|}
\hline \multirow[b]{2}{*}{ GCM } & \multirow[b]{2}{*}{$\begin{array}{l}\text { Return } \\
\text { Period }\end{array}$} & \multicolumn{2}{|c|}{ Return Level } & \multirow{2}{*}{$\begin{array}{l}\text { Changes } \\
(\%)\end{array}$} \\
\hline & & $\begin{array}{l}\text { Historical } \\
\text { period } \\
(1991- \\
2015)\end{array}$ & $\begin{array}{l}\text { Future } \\
\text { period } \\
(2006- \\
2049)\end{array}$ & \\
\hline \multirow[t]{5}{*}{ CanESM2 } & 5 & 168.14 & 158.01 & -6.02 \\
\hline & 10 & 190.67 & 190.05 & -0.33 \\
\hline & 20 & 211.10 & 222.36 & 5.34 \\
\hline & 50 & 235.90 & 265.94 & 12.73 \\
\hline & 100 & 253.35 & 299.52 & 18.22 \\
\hline \multirow[t]{5}{*}{ HadGEM2 } & 5 & 168.14 & 165.84 & -1.36 \\
\hline & 10 & 190.67 & 190.34 & -0.2 \\
\hline & 20 & 211.10 & 213.72 & 1.24 \\
\hline & 50 & 235.90 & 243.87 & 3.38 \\
\hline & 100 & 253.35 & 266.44 & 5.16 \\
\hline
\end{tabular}

(ii)

\begin{tabular}{|c|c|c|c|c|}
\hline \multirow{3}{*}{ GCM } & \multirow[b]{3}{*}{$\begin{array}{l}\text { Return } \\
\text { Period }\end{array}$} & \multirow{2}{*}{\multicolumn{2}{|c|}{ Return Level }} & \multirow[b]{3}{*}{$\begin{array}{l}\text { Changes } \\
(\%)\end{array}$} \\
\hline & & & & \\
\hline & & $\begin{array}{l}\text { Historical } \\
\text { period } \\
(1991- \\
2015)\end{array}$ & $\begin{array}{l}\text { Future } \\
\text { period } \\
(2050- \\
2080)\end{array}$ & \\
\hline \multirow[t]{4}{*}{ CanESM2 } & 5 & 168.14 & 159.84 & -4.94 \\
\hline & 10 & 190.67 & 199.93 & 4.86 \\
\hline & 20 & 211.10 & 245.58 & 16.34 \\
\hline & 50 & 235.90 & & 33.85 \\
\hline
\end{tabular}




\begin{tabular}{|c|c|c|c|c|}
\hline & 100 & 253.35 & 377.14 & 48.86 \\
\hline \multirow[t]{5}{*}{ HadGEM2 } & 5 & 168.14 & 163.35 & -2.85 \\
\hline & 10 & 190.67 & 196.68 & 3.15 \\
\hline & 20 & 211.10 & 239.52 & 13.46 \\
\hline & 50 & 235.90 & 317.86 & 34.75 \\
\hline & 100 & 253.35 & 400.50 & 58.08 \\
\hline \multicolumn{5}{|c|}{ (iii) } \\
\hline & & \multicolumn{2}{|c|}{ Return Level } & \multirow[b]{2}{*}{$\begin{array}{l}\text { Changes } \\
(\%)\end{array}$} \\
\hline GCM & $\begin{array}{l}\text { Return } \\
\text { Period }\end{array}$ & $\begin{array}{l}\text { Historical } \\
\text { period } \\
(1991- \\
2015)\end{array}$ & \begin{tabular}{|l|l} 
Future \\
period \\
$(2081-$ \\
$2100)$
\end{tabular} & \\
\hline \multirow[t]{5}{*}{ CanESM2 } & 5 & 168.14 & 200.01 & 18.95 \\
\hline & 10 & 190.67 & 236.92 & 24.26 \\
\hline & 20 & 211.10 & 272.88 & 29.27 \\
\hline & 50 & 235.90 & 319.66 & 35.51 \\
\hline & 100 & 253.35 & 354.53 & 39.93 \\
\hline \multirow[t]{5}{*}{ HadGEM2 } & 5 & 168.14 & 175.09 & 4.13 \\
\hline & 10 & 190.67 & 219.42 & 15.08 \\
\hline & 20 & 211.10 & 276.34 & 30.91 \\
\hline & 50 & 235.90 & 379.74 & 60.97 \\
\hline & 100 & 253.35 & 487.84 & 92.55 \\
\hline
\end{tabular}

\section{CONCLUSION}

A slight improvement on the delta change method has been done in this study. In particular, the delta-change method that incorporates GEV model with cyclic covariate is proposed to counter the seasonality in extreme rainfall data. The new model suggesting improvement over the stationary model based on the p-value which is highly significant (approximate to 0). GEV model with cyclic covariate on both location and scale parameters is able to capture the seasonality factor in rainfall data. Hence, a reliable delta-change model has been developed in this study. This could produce more accurate projection of rainfall in the future. In addition, this would also be very useful and beneficial to the practitioners especially in terms of establishing the future risk adaptation planning. Can study the paper's main points, need not reproduce as the conclusion the abstract. A conclusion could expand a bit on the work's significance or recommend applications and extensions.

\section{ACKNOWLEDGMENT}

I would like to thank Malaysian Department of Irrigation and Drainage (DID) for providing the rainfall data. This study was fully supported by Geran Putra - Inisiatif Putra Muda (IPM), Vote No: 9619400

\section{REFERENCES}

1. Hoar, T., Nychka, D. Statistical downscaling of the community climate system model (CCSM) monthly temperature and precipitation projections. White paper preprint, Institute for Mathematics Applied to Geosciences/ National Center for Atmospheric Research, Boulder, CO80307, 2018.

2. Gleick P.H. Methods for evaluating the regional hydrologic effects of global climate changes. J Hydrol, 88:97-116, 1986.

3. Arnell N.W. Global warming, river: flows and water resources. Wiley, Chichester, 1996.

4. Towler, E., B. Rajagopalan, E. Gilleland, R. S. Summers, D. Yates, and R. W. Katz, Modeling hydrologic and water quality extremes in a changing climate: A statistical approach based on extreme value theory, Water Resour. Res., 46, 2010, W11504, doi:10.1029/2009WR008876.

5. Sarr, M.A.; Seidou, O.; Tramblay, Y.; Adlouni, S. Journal of Hydrology: Regional Studies Comparison of downscaling methods for mean and extreme precipitation in Senegal. J. Hydrol. Reg. Stud. 4, 369-385, 2015.

6. Jenkinson, A. F. The frequency distribution of the annual maximum (or minimum) values of meteorological elements. Quarterly Journal of the Royal Meteorological Society, 81(348), 158-171, 1955.

7. Katz, R., Parlange, M., Naveau, P. Statistics of extremes in hydrology. - Adv Water Resour 25, 1287-1304, 2002.

8. Tramblay, Y., Badi, W., Driouech, F., Neppel, El. S., Servat, L.E. Climate change impacts on extreme precipitation in Morocco. Glob. Planet. Change 82-83, 104-114, 2012.

9. Sarr, M.A., Gachon, P., Seidou, O., Bryant, C.R., Ndione, J., Comby, J. Inconsistent linear trends in Senegalese rainfall data indices from 1950 to 2007. Hydrol. Sci. J. 2014.

10. Syafrina, A. H., M. D. Zalina, and L. Juneng. Historical trend of hourly extreme rainfall in peninsular Malaysia,Theor. Appl. Climatol.,120,259-285, 2014. 